\title{
Border Walls and Smuggling Spillovers
}

\author{
Anna Getmansky* \\ Guy Grossman ${ }^{\dagger}$ \\ Austin L. Wright
}

February 15, 2019

\begin{abstract}
A growing number of states are erecting physical barriers along their borders to stem the illicit flow of goods and people. Though border fortification policies are both controversial and politically salient, their distributional consequences remain largely unexplored. We study the impact of a border wall project on smuggling in Israel. We use the initial phase of the wall construction to causally estimate spillover effects on cross-border smuggling, especially vehicle theft. We find a large decrease in smuggling of stolen vehicles in protected towns and a similar substantial increase in not-yet-protected towns. For some protected towns, fortification also arbitrarily increased the length of smuggling routes. These township-level shocks further deterred smuggling (6\% per kilometer). Our findings suggest that border fortification may have uneven distributional consequences, creating unintended winners and losers.
\end{abstract}

\footnotetext{
*Department of International Relations, London School of Economics and Political Science. Address: Houghton Street, London, WC2A 2AE, United Kingdom. Email: a.getmansky@lse.ac.uk

${ }^{\dagger}$ Department of Political Science, University of Pennsylvania, and EGAP Address: Perelman Center for Political Science, 133 S. 36th Street, Philadelphia, PA, 19104. Email: ggros@sas.upenn.edu

${ }^{\ddagger}$ Harris School of Public Policy, The University of Chicago. Address: 1155 East 60th Avenue Chicago, IL 60637. Email: austinlw@uchicago.edu. We thank Alexei Abrahams, Ethan Bueno de Mesquita, Anthony Fowler, Tarek Ghani, Jeffrey Grogger, Ethan Kapstein, Dorothy Kronick, Benjamin Laughlin, Jens Ludwig, Stanislao Maldonado, Luis Martinez, Marc Meredith, Paul Poast, Jacob Shapiro, Rodrigo Soares, and Juan Vargas. We are grateful for participants at the Empirical Studies of Conflict workshop at Princeton, Economics of Crime workshop at Rosario, and at the Borders \& Boundaries Conference at Penn, for helpful comments. We also thank the United Nations Office for the Coordination of Humanitarian Affairs, Peace Now, and Israeli Police for granting access to data. This material is based upon work supported by the National Science Foundation Graduate Research Fellowship under Grant No. 2012152169 [Wright].
} 
Enhanced security efforts, as many public policies, may have unintended consequences, both positive and negative. Changes in the terror alert system in Washington DC, for example, reduced criminal activity in areas with corresponding heightened security (Klick and Tabarrok, 2005). Similarly, changes in the deployment of police units following the 2005 terrorist bombings in London reduced crime, arguably by increasing the costs of localized illicit activity (Draca, Machin and Witt, 2011). Other security policies had unintended adverse effects. For example, justice system reform in Venezuela resulted in an increase in extrajudicial killings of those whom police officers could no longer arrest (Kronick, 2018). The 2010 Dodd-Frank Act discouraged electronics manufacturers from sourcing minerals from the eastern Democratic Republic of the Congo, reducing revenue available to warlord-led militias, but also dramatically increasing infant deaths in villages near policy-targeted mines (Parker, Foltz and Elsea, 2016). ${ }^{1}$ We focus on the unintended distributional consequences of an increasingly salient public policy-border securitization. ${ }^{2}$

While efforts to regulate the movement of goods and people in and out of its territory have long been a core state activity, recently many states have intensified efforts to deny territorial access to "clandestine transnational actors," such as human smugglers, drug traffickers and terrorists. $^{3}$

Cross-border smuggling and trafficking is ubiquitous: the annual value of these illicit activities is estimated at 1.014 Trillion USD, a third of which is the value of the global drug trade. ${ }^{4}$ Trafficking in humans has also been a source of growing concerns: in 2016 alone, at least 2.5 million migrants from over 140 countries were smuggled across borders for an economic return of about $\$ 7$ billion USD (UNODC, 2018). In this paper, we use the case of Israel to study the efficacy of one effort to stem illegal cross-border smuggling: constructing

\footnotetext{
${ }^{1}$ Unintended negative externalities are not limited to the security domain: a cash transfer program in Mexico increased deforestation (Alix-Garcia et al., 2013) and women's inheritance rights reform in India worsened sex-ratio by encouraging female feticide (Bhalotra, Brulé and Roy, 2018).

${ }^{2}$ For distributional effects of policy choices in non-security domains, see Hacker and Pierson $(2010)$.

3 Andreas (2003) defines clandestine transnational actors as non-state agents who operate across national borders in violation of state laws and who attempt to evade law enforcement efforts.

${ }^{4}$ See Havocscope Global Disruption Index Breakdown.
} 
physical border walls; a highly politicized policy response to border instability.

In the past two decades, over 30 countries have constructed physical walls along their borders to limit unauthorized border crossing (Figure SI-1). And irrespective of whether a physical wall is primarily intended to minimize smuggling of people or goods, all forms of illicit transnational activities are treated as a national security concern (Wastl-Walter et al., 2014).

In the Israeli case, the primary reason to erect a physical barrier was to stop the movement of terrorists from the West Bank into Israel. Making it more difficult for militants to cross the border, the wall has also increased the costs of smuggling stolen vehicles from Israel into the West Bank. Notably, about 80 percent of stolen vehicles are transported to the West Bank, where they are dismantled for spare parts and sold to car shops in Israel (State Comptroller, 2014). The Israeli case thus provides an opportunity to study the effect of physical border barriers on the smuggling activities and strategies of transnational criminal gangs, and ultimately, the welfare implications of border walls for the local population.

There is a growing literature that explores the determinants of border fortification (Hassner and Wittenberg, 2015; Jones, 2012; Carter and Poast, 2017). Yet, we know relatively little about the consequences and efficacy of border walls. Construction of the Israeli wall was staggered in a manner unrelated to criminal activity, with Northern townships receiving protection earlier than Southern border towns. Among protected localities, the wall also blocked some, but not all, of the most-preferred smuggling routes. We take advantage of this feature of Israel's border wall project to draw causal inferences about the efficacy and distributional consequences of (partial) fortification with respect to cross-border smuggling activity.

We leverage a collection of novel data enabling us to track both border wall completion over time and the monthly number of vehicles stolen at the township level. We report two main results. First, a 'naive' estimation of the impact of border fortification on car theft - comparing protected to yet-to-be protected towns - suggests a large but misleading reduction in crossborder smuggling. This approach, which besets a large number of past crime studies, assumes 
that smuggling activity does not relocate geographically. However, once spatial spillovers are accounted for, we find that smuggling decreases in places protected by the wall and increases at similar rates in unprotected towns where the border wall has not yet been built. The Israeli border wall thus had little effect on overall crime, yet it had distributional consequences due to spatial crime displacement.

Second, we further explore whether and how criminal gangs respond (rationally) to border fortification efforts - i.e., to changes in smuggling costs. Here, we use the location of official border crossings to identify town-specific changes in optimal length of smuggling routes before and after barrier construction. We find that idiosyncratic smuggling shocks are correlated with shifts in smuggling activity. On average, each additional kilometer traveled due to the border wall corresponds to about a $6 \%$ decrease in monthly vehicle theft. Importantly, this finding helps to alleviate possible concerns that the reduction in cross-border smuggling in newly protected towns is not due to localized costs of crime, but to unobserved contemporaneous confounders. In addition to demonstrating the responsiveness of local gangs to shifting costs of illicit activity - in itself, a contribution to the literature on crime determinants - this analysis helps explain an additional distributional outcome: why some localities in protected areas experienced significantly larger reductions in smuggling than others.

Our results suggest that even when border walls raise smuggling costs, they do little to reduce cross-border smuggling if fortification is partial, demand for illicit goods is stable and smuggling can be displaced to neighboring regions with minimal transaction costs. Since nearly all border walls are partial barriers, opportunities for smuggling spillovers abound. Additional analysis - included in the appendix published online - reveals that smugglers operating in protected areas likely substituted into alternative criminal enterprises, as the cost of crossborder smuggling increased. Thus a narrow focus on a single type of crime or on a single region - ignoring spatial spillovers and gangs' adaptive behavior - might result in misleading conclusions regarding the efficacy of partial border walls.

This paper makes contributions to several bodies of work, most notably to the growing 
literature on the effects of border securitization. Laughlin (2018) finds that the construction of fences along the U.S.-Mexico border caused at least 2,000 additional deaths in localities near smuggling routes. Relatedly, Massey, Pren and Durand (2016) find that the securitization of the U.S. southern border increased the number of undocumented migrants. Migrants extend the duration of their stays north of the border, in part, to cover the increased costs of border crossing. The border fortification project we study shares many features with other cases of border walls - in particular, the stark economic disparities between Israel and the West Bank that encourage illicit goods smuggling. Our research clarifies the consequences of border fortification, especially when such efforts raise the costs of cross-border smuggling along some, but not all, segments of a border. Specifically, our findings highlight distributional consequences of partial walls and underscore their limited efficacy due to transnational gangs' strategic adaptation.

\section{Auto Theft in Israel}

Cross-border smuggling of stolen property remains a prominent threat to public order and border stability in Israel. Auto theft especially has been increasing since the mid-1980s, and is considered among the highest in the world. ${ }^{5}$

Car theft in Israel is perpetrated by gangs, operating within "a well-established and organized criminal industry" (Herzog, 2002, 716). These gangs are comprised of Palestinians from Israel and from the West Bank, and in some cases also involve Israeli Jewish criminals. Prior to the border wall construction, most but not all stolen vehicles were transported to the West Bank through uncontrolled and unpaved routes. Often, though, stolen cars were driven east through border checkpoints located on main roads connecting Israel and the West Bank. In such cases, gangs use scouts to report police and soldiers' alertness. Almost all stolen vehicles are driven directly to West Bank chop shops, which strip the vehicles of their parts. In many cases, the stolen parts are sold to Israeli vehicle repair shops (State Comptroller, 2014).

\footnotetext{
5 "Stolen to Order: Israel's Car Thieves Are Getting Choosier." Haaretz: October 15, 2013. The direct economic damage caused by the theft of vehicles is estimated at more than NIS 1 billion a year.
} 
We focus on the period between late 2000 - the eruption of the Second Intifada that triggered the staggered wall construction - and early 2004. Importantly, legislation and enforcement did not experience major changes during this period, helping to isolate the effect of the construction of the border wall.

While a 1998 law banned the import of used spare parts from the West Bank, the ban went into effect only after an amendment was passed in 2005. Moreover, a specialized police unit (ETGAR) devoted to preventing and prosecuting auto thefts was fully operational during the study's period (but was dismantled in 2005 and reorganized in 2006). ${ }^{6}$

\section{Research Design}

Three features of the Israeli barrier make it a well-suited case for examining the unintended consequences of border securitization efforts on transnational illicit smuggling activity.

First, the wall's route and the sequence of its construction were exogenous to auto theft rates, driven instead by security concerns and litigation of route appeals. Erecting a physical 'separation barrier' gained popular support with the outbreak of the Second Intifada in September 2000 (Brom and Shapir, 2002). Between the onset of the uprising and mid-2002, 78 Palestinians committed suicide attacks against Israeli targets; the majority of terrorists hailing from the West Bank's Northern region. This led the Israeli cabinet to prioritize wall construction in the north to "improve and reinforce the readiness and operational capability in coping with terrorism" (Lein, 2003). The border wall's route was determined on the basis of the Green Line (the pre-1967 border), with deviations intended to encompass as many Jewish settlements as possible, so as to enable their de facto annexation by Israel (Hareuveni, 2012). Further delays in constructing the wall along the southern part of the West Bank were due to legal appeals of Palestinians against the proposed route and its associated land confiscations, and, in several cases, because of environmental considerations. ${ }^{7}$ That regional prioritization in wall construction was unrelated to auto theft is central for the study's identification strategy.

\footnotetext{
${ }^{6}$ Based on in-person interviews we had conducted with police officers and industry experts in Israel.

7 "Cabinet Due to Again Approve Controversial Section of West Bank Barrier." Haaretz, Sept 19, 2015.
} 
Second, the Israeli border wall increased the expected cost of crime participation by making the transportation of stolen vehicles to the West Bank riskier. The wall comprises a multilayered system of chain-link fences, electronic sensors that trigger signals to nearby command centers, and electronic cameras equipped with night vision (Dolphin, 2006). Wall sections close to Palestinian urban areas or to Israeli highways are 25 feet tall and 10 feet wide concrete slabs (see Figure 1a). The remaining barrier consists of chain-link fences and barbed wire, trenches, and patrol roads (see Figure $1 \mathrm{~b}$ ).

Figure 1: Separation barrier, pictures from $\mathrm{OCHA}(2014,2)$.

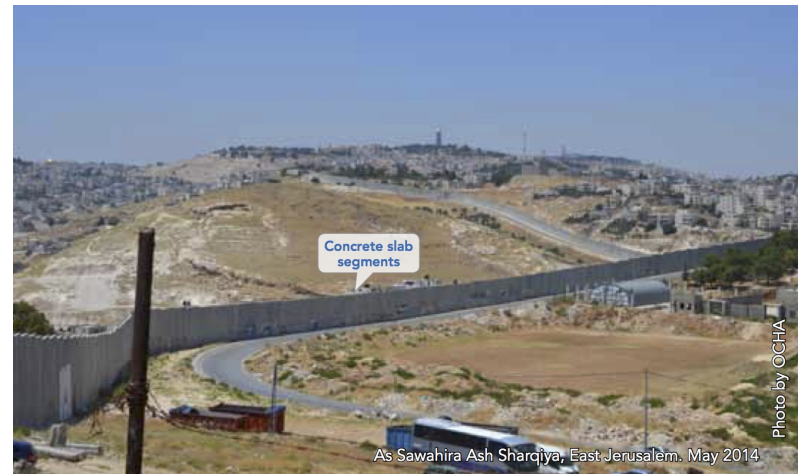

(a) Concrete barrier

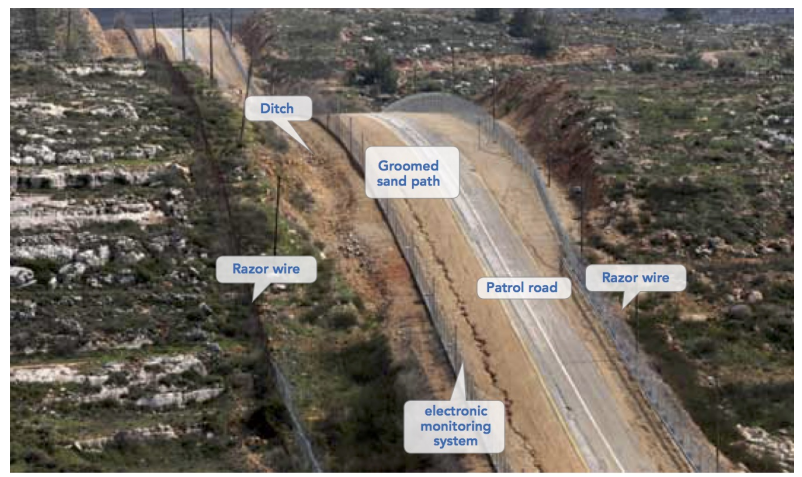

(b) Chain-link barrier

Following the wall construction, all stolen vehicles smuggled out of Israel into the West Bank have therefore had to travel along main roads and pass through guarded checkpoints. Thus, the barrier increased the average length of travel between Israel's northern border localities and the West Bank, which directly increases apprehension probability. Moreover, though security forces mostly focus on monitoring entry into Israel from the West Bank, and pay less attention to vehicles with Israeli license plates driving into the West Bank, they still may stop a stolen vehicle if alerted quickly. This also increases the expected cost of cross-border smuggling of stolen vehicles.

Third, the visibility of the border wall makes the increased risk of apprehension salient to potential smugglers. Together, these features of the Israeli border wall increase our confidence that changes in crime incidence are a rational response to situational measure externalities. 


\section{Data and Variable Description}

Our unit of analysis is the locality-month. We focus on Jewish Israeli localities (municipalities, local councils, towns, etc.) west of the Green Line, thereby excluding Jewish settlements in the West Bank and Arab localities in Israel proper. The number of localities in a given year ranges from 914 to 1,050, reflecting both the establishment of some new localities and merging of existing ones in various years.

The study's key dependent variable is the number of reported vehicle thefts per 1,000 residents in a given locality-month. We obtained these data from the Israeli Police using the Israeli Freedom of Information Law.

We employ a spatial overlap design to assign localities to three treatment classifications based on their geographic zone (see Figure 2). Starting with the northern part of the West Bank, the thick black line ('Separation Barrier 2002') represents the first segment that was built starting from June 2002. The gray thick line ('Separation Barrier 2003') depicts an extension constructed in early 2003. These lines are the basis for assigning localities to the Northern treatment area. The treatment boundary extends from the edges of separation barrier to the western coastline (approximately 25 kilometers) and an equivalent distance to the north. The resulting boundary rectangle excludes areas to the south and the east of the barrier. A spatial intersection was used to identify localities within this boundary.

The dotted lines ('Separation Barrier 2006') depict the south and central West Bank areas, where the wall was constructed only after 2005. Localities west and south to the post-2005 line are assigned to the Southern control zone. For these localities, the expected cost of stealing vehicles remained constant throughout the study's period; however, post June-2002 they became increasingly vulnerable to possible crime displacement from treatment localities. Consistent with our classification of treatment towns, we use a spatial intersection to identify Southern townships. ${ }^{8}$

\footnotetext{
${ }^{8}$ We note two minor differences between our classification of Northern and Southern localities. First, the control group boundary extends approximately 40 kilometers from the 2006 line to the western coastline and
} 
Figure 2: Map describes study area and assignment of localities to treatment status.

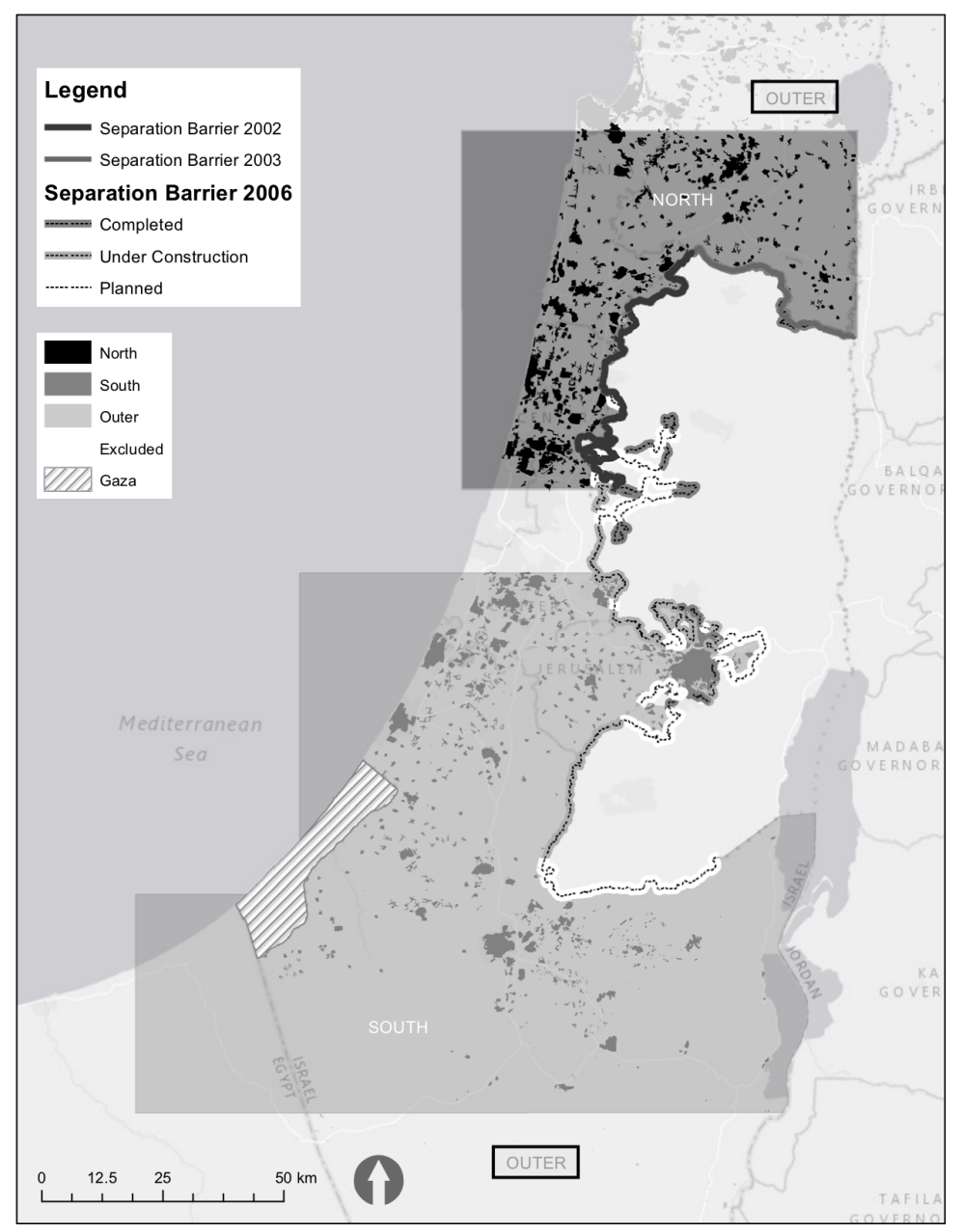

We classify Israeli localities outside the two shaded regions (above the Northern zone and below the Southern area) as an "Outer" group. These towns are located sufficiently far from West Bank chop shops, such that they are unaffected by fortification efforts along the West Bank border. Vehicles stolen from Outer localities in northern Israel are either dismantled in chop shops in the Galilee region or smuggled to Lebanon; most vehicles stolen from Outer localities in southern Israel are smuggled to Egypt. The Outer group is therefore a residual category that is essential for estimating general equilibrium securitization effects. As we demonstrate below, our findings are robust to alternative treatment and control assignment criteria.

an equivalent distance to the south, reflecting the greater distance to the coastline. Second, we exclude Gaza from the control area. 
In our baseline analysis, we define a binary variable Treatment that takes the value of one for all localities in the treated Northern region and the value of zero for localities in the unprotected Southern (or control) area. Using this specification, we are able to test a partial equilibrium common in the literature [e.g., DiTella and Schargrodsky (2004)]. In our general equilibrium specifications, we replace this specification with two binary variables. In one specification, we compare the Northern localities to the Outer localities. In the other specification we compare the Southern localities to the Outer localities. This design most closely follows Donohue, Ho and Leahy (2015). We define the Post period as all months from June 2002, when construction of the barrier along the Northern (but not Southern) border began.

We control for a variety of locality-level attributes that can affect auto theft. In particular, we include a continuous measure of population size, a binary measure of urbanization, a continuous measure of distance from the Green Line (and its squared term), municipal administrative designation, and flexible time trend. These measures are taken from the Israeli Central Bureau of Statistics. In robustness checks, we also control for locality's socio-economic status and exposure to terrorism. A more detailed description of the data can be found in the online appendix (see Section B).

Summary statistics are in Table SI-2. The data show that in the Northern localities the mean number of monthly vehicles stolen per 1,000 residents dropped from 1.02 in the preconstruction period to 0.56 in the post-construction period. In the Southern localities, car theft increased from 0.87 to 1.07 . In the Outer localities, we observe a statistically insignificant shift in mean theft from .34 to .29 .

\section{Estimation Strategy}

We use a series of difference-in-difference regressions to estimate the effect of barrier construction on auto theft. Our base model is captured by equation 1: 


$$
Y_{j t}=\alpha+\beta_{1} \text { Treatment }_{j}+\beta_{2} \text { Post }_{t}+\beta_{3} \text { Treatment }_{j} \times \text { Post }_{t}+\eta_{t}+\gamma X_{j t}+\epsilon_{j t}
$$

where $Y_{j t}$ is the number of vehicles stolen per 1,000 residents in locality $j$ in month $t$; Treatment $_{j}$ is a treatment indicator; Post $_{t}$ is the indicator for the post-construction period (June 2002); $\eta_{t}$ denotes a linear month trend, which accounts for secular growth in the demand for stolen cars; $X_{j t}$ is a vector of locality controls; and $\epsilon_{j t}$ is the locality error term. In all models we cluster standard errors at the locality level. In the SI, we also introduce estimates that leverage unit and time fixed effects. In the main analysis, the coefficient of interest is $\beta_{3}$.

\section{Satisfying Identification Assumptions}

The validity of our estimation strategy relies on two core assumptions. First, barrier construction must not coincide with possible changes in policy activity. We show the validity of this assumption in SI (Section C), where we analyze data we obtained from the Israeli police on both police deployment (Figures SI-2 and SI-3) and on suspects caught while operating stolen vehicles (Figures SI-4 and SI-5).

Second, as in all difference-in-differences estimations, we assume parallel trends in auto theft prior to wall construction. We visualize these trends in Figure 3 in which we plot the monthly mean of car theft (per 1,000 residents) by treatment group as a percentage of the group's pre-wall mean. The pre-wall trends in car theft across treatment groups appear parallel with some noisiness early in the study period. In the six months before and as wall construction begins, all regions have similar crime rates. Starting one month into wall construction, however, car theft in the North drops significantly to roughly $50 \%$ of the prewall average, while car theft in the South begins to steadily increase. As expected, we observe marginal fluctuations around the pre- (and post-) wall mean in the Outer localities. We present

additional formal tests of the parallel trends assumption in the online appendix (Section E). 
Figure 3: Trends in car theft (normalized by population) by treatment group, before and after wall construction (vertical line).

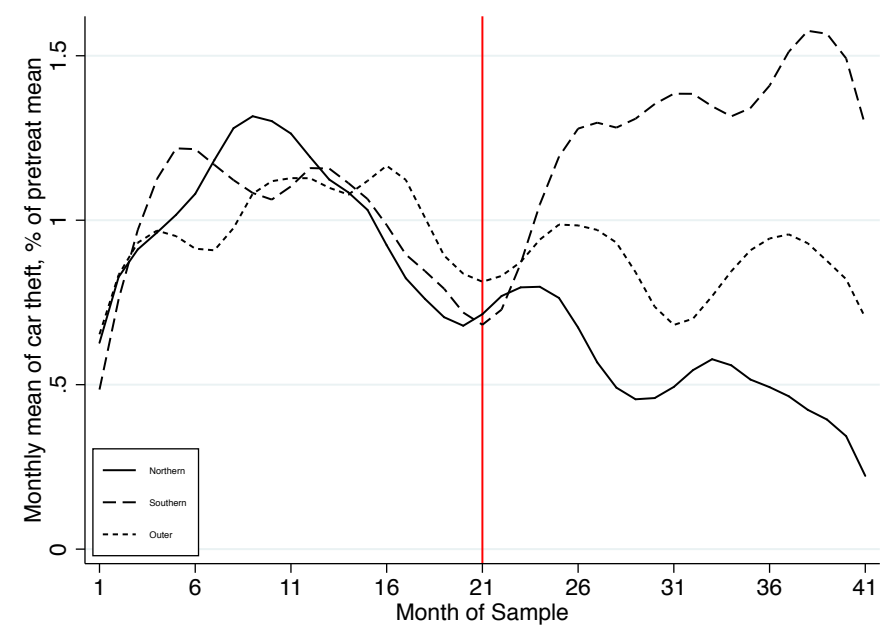

\section{Results: Deterrence and Displacement}

We find that auto theft significantly declined in Northern localities after the border wall was constructed compared to Southern localities (Table 1, column 1). This result, however, potentially incorporates two effects: deterrence and displacement. If the construction of the border wall causes significant externalities to southern localities, the baseline models would overstate the true treatment effect.

To address this concern, we (separately) compare car theft in the Northern and Southern localities to Outer localities, where the potential for crime spillovers should be limited. Results

reported in Table 1 (see North vs. Outer and South vs. Outer columns) suggest that a substantial amount of the reduction in car theft in the protected Northern localities was displaced to Southern towns. In the post-wall period, car theft dropped in Northern localities by 0.4 vehicles per 1,000 residents compared to Outer areas, and the South experienced 0.3 additional stolen vehicles per 1,000 residents relative to Outer localities. These shifts are equivalent to a $41 \%$ decrease in car theft among Northern localities and a $34 \%$ increase across Southern localities. The grand mean in car theft does not shift substantially after the wall is constructed (.73 vs. .67), suggesting the reduction in auto theft in the North is almost entirely 
offset by an increase in the South.

Table 1: Barrier construction and auto theft: deterrence and displacement

\begin{tabular}{lccc} 
& \multicolumn{3}{c}{ Diff-in-Diff } \\
\cline { 2 - 4 } & $\begin{array}{c}\text { North vs. } \\
\text { South }\end{array}$ & $\begin{array}{c}\text { North vs. } \\
\text { Outer }\end{array}$ & $\begin{array}{c}\text { South vs. } \\
\text { Outer }\end{array}$ \\
\hline Treatment & 0.097 & $0.267^{*}$ & $0.211^{* *}$ \\
& $(0.114)$ & $(0.142)$ & $(0.098)$ \\
Post & $0.186^{* * *}$ & $0.102^{* *}$ & $-0.230^{* * *}$ \\
& $(0.056)$ & $(0.044)$ & $(0.048)$ \\
Treatment $\times$ Post & $-0.671^{* * *}$ & $-0.415^{* * *}$ & $0.256^{* * *}$ \\
& $(0.079)$ & $(0.071)$ & $(0.057)$ \\
\hline $\mathrm{N}$ & 24985 & 23716 & 25069 \\
Clusters & 617 & 587 & 620 \\
\hline
\end{tabular}

Note: Model estimates from diff-in-diff regressions formalized in equation 1 North vs. South column compares localities protected by the Northern part of the wall to unprotected areas west of the Southern border with the West Bank; North vs. Outer column compare instead Northern (protected) localities to unprotected Outer areas that are too far to be affected by wall construction; and South vs. Outer column reports the comparison between two types of unprotected areas: Southern (yet-to-be protected) localities that are exposed to spillovers and Outer localities that are not.

- Robust standard errors in parentheses, clustered by locality.

${ }^{*} \mathrm{p}<0.10,{ }^{* *} \mathrm{p}<0.05, * * * \mathrm{p}<0.01$

In the online appendix, we introduce several robustness checks: (i) incorporate fixed effects into the baseline diff-in-diff specification; (ii) add lags of the outcome; (iii) drop pre-treatment periods with potential trend breaks; (iv) narrow the main sample to ten months prior to and after treatment; (v) incorporate district-specific time trends; (vi) cluster our standard errors to account for the industrial organization of crime; (vii) exclude potential outliers; (viii) incorporate mixed religion localities in our main sample; (ix) account for intensity of terrorist activity; (x) address changes in socio-economic development by locality; (xi) construct alternative treatment and control classifications. These results are highly consistent with our main findings.

\section{Smuggling Route Disruption}

Core criminal behavior models suggest that if the perceived risk of apprehension in locality $j$ increases due to some visible prevention measure, criminal activity in that locality should be reduced or displaced (Chalfin and McCrary, 2017). The border wall introduced a common shock by forcing all thieves operating in localities west of the Northern part of the Green Line to drive through checkpoints when transporting stolen vehicles into the West Bank. However, 
the extent to which the construction of the wall disrupted routes previously taken by smugglers varied from one locality to another. This caused the risk of apprehension to shift as a function of locality-specific shocks (in addition to the common shock of barrier construction). In this section, we use granular road network data to investigate the distributional consequences of border fortification within the protected Northern zone.

To identify the degree to which trafficking routes were disrupted in newly secured Northern localities, we collect data on the road network connecting Israel and the West Bank from Open Street Map repositories. Based on secondary information and interviews with Israeli police officers and criminologists, we identify the locations where vehicles were most frequently taken to be dismantled. In the Northern West Bank, auto theft activity is concentrated out of the city of Nablus; in the West Bank's South, this activity is largely based around Hebron. With these data in hand we build on a route optimization problem detailed by Dell (2015) and calculate optimal paths from each locality to the nearest stolen vehicle destination.

We begin with a directed graph of all paved vehicular roads in Israel and the West Bank $R$, which is composed of intersections $N$ and roadways $E$ (so, $R=(N, E)$ ). Smugglers move stolen vehicles from Israeli localities to Palestinian chop shops, where vehicles are dismantled. Each smuggler attempts to minimize the risk of apprehension and input costs of transit. For simplicity, let each roadway $e \in E$ have a cost function determined by the length $\left(l_{e}\right)$ of the road, so the risk and cost of traveling along a given road is equal to $c_{e}\left(l_{e}\right)$. If traversing $n \in N$ is costless, then the total cost of a potential smuggling route $p$ is $V(p)=\sum_{e \in p} c_{e}\left(l_{e}\right)$. This term covers both the opportunity cost of crime, as well as the risk of apprehension. ${ }^{9}$

Let $P_{L, C S}$ denote the set of all possible routes between localities $L$ and "chop shops" $C S$ in the pre-construction period. Criminals optimize routes such that:

$$
\min _{p \in P_{L, C S}} V(p)
$$

\footnotetext{
${ }^{9}$ The degree to which a route is disrupted - and lengthened - impacts both the risk of apprehension while transporting the vehicle (length of road driven in stolen vehicle) and opportunity costs of the criminal transaction (amount of time spent driving the vehicle).
} 
After the construction of the wall, some (but not all) of these paths are disrupted. To calculate route disruptions, we constrain traffic in the post-construction period to cross from Israel proper to the West Bank using main roads and thus to necessarily pass through security checkpoints. That is, edges $E$ in $R$ that bisect the separation barrier $\mathbf{B}$ are eliminated from the set of roadways that could be utilized to pass from Israel to the West Bank. By implication, unpaved or semi-paved roads are dropped from the network after barrier construction. Denote the remaining traversable pathways and intersections as $E^{\prime}$ and $N^{\prime}$.

Following the construction of the separation barrier, for every path $p^{\prime}$, the cost of travel is $V\left(p^{\prime}\right)=\sum_{e^{\prime} \in p^{\prime}} c_{e^{\prime}}\left(l_{e^{\prime}}\right)$, where $e^{\prime}$ can only be drawn from $E^{\prime}$. For some localities, potential smugglers employ the same route in the presence of the security barrier. To clarify, for these towns, the $p$ in $P_{L, C S}$ and $p^{\prime}$ in $P_{L, C S}^{\prime}$ that minimize transit costs are identical $\left(p=p^{\prime}\right)$. For other localities, introduction of the checkpoints constraint increases the cost of travel substantially. For these localities, $p<p^{\prime}$. See Figure SI-11 for a visualization of the optimal smuggling routes, before and after barrier construction.

For all Northern localities, $\frac{p^{\prime}}{p} \geq 1$. Under a binary treatment definition, route disruption is considered uniform. Yet disruption differentially raises the costs of auto theft when $\frac{p^{\prime}}{p}$ $>$ 1. To test if route disruption implies heterogeneous treatment effects, we calculate $d$, treatment intensity, simply as $\frac{p^{\prime}}{p}$. Practically, $d$ exceeds the binary treatment condition by the percentage of the pretreatment route length disruption. We note that just over a third of Northern localities have a value of $d>1$.

How did idiosyncratic route disruption affect population normalized auto theft rates in the post-construction period? In Figure 4, we plot the differences in monthly car theft (left vertical axis) as a function of both $p$ (horizontal axis) and $d$ (right vertical axis). We find that auto theft reduction follows $d$ very closely. Where the cost of criminal activity, $d$, is monotonically increasing -from the "border" until approximately 42 kilometers from Nablus - the decrease in auto theft is also growing larger. As the average rate of disruption begins decreasing - for localities that are located more than 42 kilometers from Nablus - the reduction in criminal 
activity is still substantial, but smaller in magnitude. This visual evidence suggests localities that experienced the greatest drop in auto theft activity are also those that benefitted from the largest increases in smuggling costs due to barrier-induced disruption of trafficking routes.

\section{Figure 4: Impact of smuggling path disruption on auto theft intensity.}

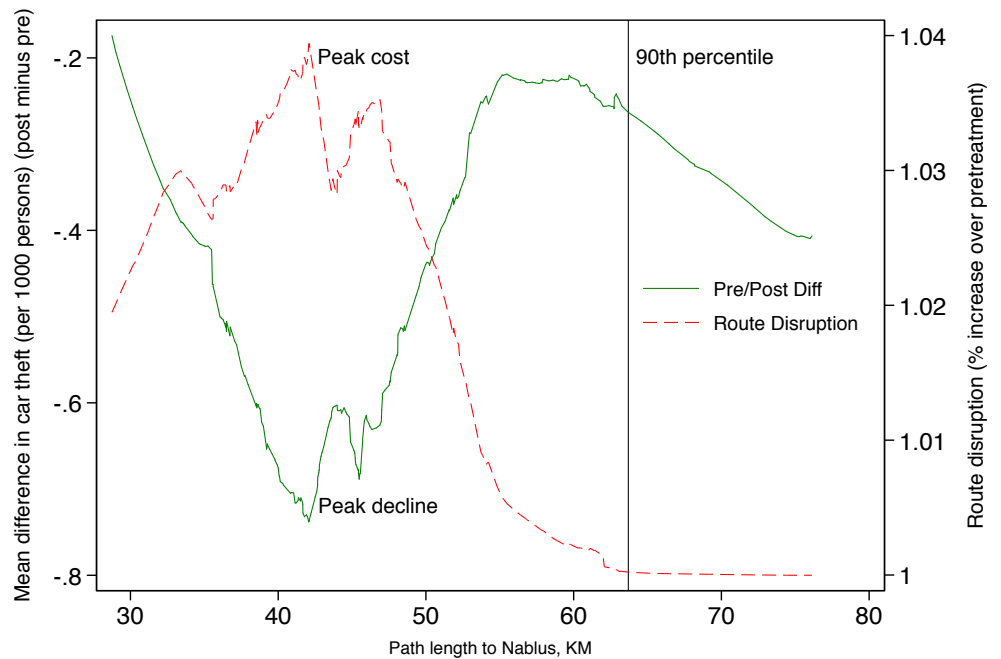

\section{Decomposing Smuggling Shocks Effects}

To estimate the effects of route disruption on car theft, we begin by comparing Northern and Outer localities using the same diff-in-diff model formalized in equation 1 . The only difference is that Treatment $_{j}$ is now measured as $d$ (i.e., $\frac{p^{\prime}}{p}$ ). For northern localities with no shift in smuggling routes, Treatment ${ }_{j}$ equals 1. For treated localities with a shift in smuggling routes, Treatment $_{j}$ exceeds 1 (with a max of 1.54 , indicating a $54 \%$ increase in route length due to the border wall construction). In this specification, $\beta_{3}$ captures the aggregate (or average) effect of treatment intensity.

Effectively, this allows estimating the combined effect of the common shock (the construction of the barrier) and the disruption of smuggling routes. Here, the interaction takes the value 1 for Northern localities after the barrier is built if the preferred smuggling route does not change (i.e., the route happens to go through a checkpoint). If the route does change, we measure the degree of disruption as a percentage. Compared with the results in column 2 of Table 1, Table 2 column 1 suggests larger reductions in car theft as route disruption increases. 
At the observed maximum disruption, car theft is reduced by roughly $60 \%$ (compared to $42 \%$ in the base specification). In column 2, we similarly estimate the effect of disruption in kilometers to ease interpretation. Each additional kilometer of the smuggling route is associated with a decrease in auto theft of roughly $6 \%$.

Table 2: Impact of smuggling route disruption on auto theft: common shock and heterogenous treatment intensity

\begin{tabular}{lccc} 
& \multicolumn{3}{c}{ North Vs. Outer } \\
\cline { 2 - 4 } & $\begin{array}{c}\text { Aggregate Effect: } \\
\text { Common shock } \\
\text { disruption }\end{array}$ & $\begin{array}{c}\text { Degree of } \\
\text { Disruption }(\mathrm{KM})\end{array}$ & $\begin{array}{c}\text { Disaggregate Effects: } \\
\text { Common shock vs. } \\
\text { Common shock } \\
\text { + disruption }\end{array}$ \\
\hline Treatment $(d \geq 1)$ & $\begin{array}{c}0.258^{*} \\
(0.139)\end{array}$ & \\
Post & $0.103^{* *}$ & $-0.078^{*}$ & \\
Treatment $(d \geq 1) \times$ Post & $(0.044)$ & $(0.040)$ & $(0.044)$ \\
Treatment $(\Delta \mathrm{KM})$ & $-0.408^{* * *}$ & \\
Treatment $(\Delta \mathrm{KM})$ & $(0.070)$ & 0.022 & \\
$\times$ Post & & $(0.029)$ & 0.081 \\
Treatment $(d=1)$ & & $-0.059^{* * *}$ & $(0.134)$ \\
Treatment $(d=1)$ & & & $-0.319^{* * *}$ \\
$\times$ Post & & & $(0.066)$ \\
Treatment with disruption $(d>1)$ & & & $0.531^{* *}$ \\
Treatment with disruption $(d>1)$ & & & $(0.230)$ \\
$\times$ Post & & & $-0.546^{* * *}$ \\
\hline $\mathrm{N}$ & & & $(0.138)$ \\
Clusters & & & 23716 \\
\hline
\end{tabular}

Note: Model 1 allows the binary treatment status to exceed 1 in cases where routes are disrupted. The maximum observed increase in route length is $54 \%$, so the maximum value of this measure is 1.54 . The sample compares Northern and Outer localities. Notice that the estimated effect differs from Table 1 Column 2 because our treatment variable is no longer binary. The estimated effect represents an average across all treated Northern townships. Model 2 studies disruption using the absolute increase in route length in kilometers. Model 3 relaxes Model 1 and enables us to disaggregate treatment effects within Northern localities. "Treatment" takes the value 1 if a locality is in the treated zone (Northern) and does not experience an increase in route length (otherwise 0). "Treatment with disruption" takes the value of $d$ (see text) if a locality is in the treated zone (Northern) and does experience an increase in route length (otherwise 0). All models control for locality factors as described in the main text.

- Robust standard errors in parentheses, clustered by locality.

${ }^{*} \mathrm{p}<0.10,{ }^{* *} \mathrm{p}<0.05,{ }^{* * *} \mathrm{p}<0.01$

While informative, our baseline specification (Table 2 columns 1 and 2) is unsuited to capture possible heterogeneity across treated but undisrupted localities and those that did experience disruption. It is possible, for example, that the main effects are driven entirely by localities that experienced a route disruption and our aggregate specification simply masks these subgroup effects. To investigate this, we construct two treatments variables. The first takes the value 1 if a locality is treated but experiences no route shock (and 0 otherwise). The 
second takes the value of $d$ if a unit is treated and experiences a route shock (and 0 otherwise). These classifications are exclusive (not nested) and allow us to estimate disaggregated heterogeneous effects more precisely (if they exist).

We find strong evidence that the barrier alone served to deter auto theft, at least locally (Table 2 column 3). Even if the preferred route did not change after the border wall was constructed, auto theft still declined significantly in the north as thieves needed to transport the vehicles through newly fortified checkpoints. For these localities, auto theft declined by roughly 0.32 vehicles per 1,000 residents (or $32 \%$ relative to the pre-construction auto theft levels). If, however, the barrier forced smugglers to reroute, the reduction in auto theft was further enhanced. At the maximum disruption level (54\% increase in route length), disruption resulted in an additional drop of 0.51 auto thefts per 1,000 residents. In total, this shift represents an $83 \%$ decline in car theft.

\section{Conclusion}

In this paper, we study a highly salient but poorly understood public policy: border securitization. Drawing on novel microdata, we examine the distributional consequences of a border wall project in Israel that is comparable in scale and technology to the proposed expansion of the U.S. border wall. We use the initial phase of wall construction to estimate the impact of border fortification on cross-border smuggling. Importantly, the construction project was staggered in a manner unrelated to traffic exiting Israel, allowing us to draw causal inferences about the impact of border fortification on smuggling behavior.

We find evidence that the border wall lead to a notable reduction in vehicle theft in townships 'protected' during the initial phase of construction. However, smuggling activity was displaced to nearby border localities that were 'unprotected' by the wall. We also estimate township-specific changes in the costs of smuggling. These results clarify the mechanism linking border securitization to reduced localized smuggling in the fortified region. Taken together, these results help us better understand how the unintended consequences of policy- 
making can have uneven distributional effects.

In the online appendix, we use arrest records and data on home invasions to better understand the mechanisms driving the smuggling spillovers we observe in our main results. Our descriptive evidence suggests that smugglers from the northern part of the West Bank did not relocate after the partial wall was constructed (i.e., spillovers are due to increased production by southern gangs). Instead, they likely shifted from smuggling to other illicit activities, including burglaries, thereby increasing insecurity-the very reason for building the wall in the first place. Theoretically, these findings shed light on the strategic response of criminal gangs to border fortification, especially when such efforts only partially strengthen existing institutions. Our study's core findings - especially the minimal overall effect on smuggling, the redistributive implication of the wall construction, and the substitution by affected gangs to other forms of domestic crime - also have clear implications for current policy debates regarding the efficacy of border walls.

The fact that our study uses data from a single case naturally raises external validity concerns. Specifically, one may worry that our primary outcome of interest - car theft-is not representative of the class of smuggled goods. We believe, however, that the intuition of our argument applies to a range of illicit activity - including large-scale drug supply chains and human trafficking - where the costs of criminal operations may be influenced by border interventions that constrain traffic by vehicle. More so, even though car theft is generally a non-violent form of smuggling, other types of smuggling may involve or trigger violence.

We conclude by noting that many human activities beyond illicit smuggling are affected by extensive border securitization measures. In the Israeli case, the separation barrier has also made it more difficult for Palestinian households to access their arable land and to work in Israel and for families on both sides of the barrier to reunite. Thus any analysis of the impact of border fortification measures on aggregate welfare may need to take a more holistic approach than the limited focus on crime adopted herein. 


\section{References}

Alix-Garcia, Jennifer, Craig McIntosh, Katharine RE Sims and Jarrod R Welch. 2013. "The ecological footprint of poverty alleviation: evidence from Mexico's Oportunidades program." Review of Economics and Statistics 95(2):417-435.

Andreas, Peter. 2003. "Redrawing the Line: Borders and Security in the Twenty-First Century." International Security 28(2):78-111.

Bhalotra, Sonia, Rachel Brulé and Sanchari Roy. 2018. "Women's inheritance rights reform and the preference for sons in India." Journal of Development Economics .

Brom, Shlomo and Yiftah Shapir. 2002. Erecting a Separation Fence. In An Update on Political and Strategic Developments in the Middle East, ed. Mark A. Heller. Vol. 42 Tel Aviv, Israel: Tel Aviv: Jaffe Center for Strategic Studies.

Carter, David B and Paul Poast. 2017. "Why do states build walls? Political economy, security, and border stability." Journal of Conflict Resolution 61(2):239-270.

Chalfin, Aaron and Justin McCrary. 2017. "Criminal Deterrence: A Review of the Literature." Journal of Economic Literature 55(1):5-48.

Dell, Melissa. 2015. "Trafficking Networks and the Meixcan Drug War." The American Economic Review 105(6):1738-79.

DiTella, Rafael and Ernesto Schargrodsky. 2004. "Do Police Reduce Crime? Estimates Using the Allocation of Police Forces After a Terrorist Attack." The American Economic Review 94(1):115-133.

Dolphin, Ray. 2006. The West Bank Wall: Unmaking Palestine. Pluto Press London.

Donohue, John J, Daniel E Ho and Patrick Leahy. 2015. Do Police Reduce Crime? A Reexamination of a Natural Experiment. In Empirical Legal Analysis: Assessing Performance of Legal Institutions, ed. Yun-Chien Chang. New York, NY: Routledge.

Draca, Mirko, Stephen Machin and Robert Witt. 2011. "Panic on the Streets of London: Police, Crime, and the July 2005 Terror Attacks." The American Economic Review 101(5):2157-2181.

Hacker, Jacob S and Paul Pierson. 2010. Winner-Take-All Politics: How Washington Made the Rich Richer-and Turned Its Back on the Middle Class. Simon and Schuster.

Hareuveni, Eyal. 2012. Arrested Development: The Long Term Impact of Israel's Separation Barrier in the West Bank. B'Tselem.

Hassner, Ron E. and Jason Wittenberg. 2015. "Barriers to Entry: Who Builds Fortified Boundaries and Why?" International Security 40(1):157-190.

Herzog, Sergio. 2002. "Empirical Analysis of Motor Vehicle Theft in Israel, 1990-97." British Journal of Criminology 42(4):709-728. 
Jones, Reece. 2012. Border Walls: Security and the war on terror in the United States, India, and Israel. Zed Books Ltd.

Klick, Jonathan and Alexander Tabarrok. 2005. "Using Terror Alert Levels to Estimate the Effect of Police on Crime*." Journal of Law and Economics 48(1):267-279.

Kronick, Dorothy. 2018. "Vagaries of Police Behavior." Unpublished Manuscript.

Laughlin, Benjamin. 2018. "Border Fences and the Mexican Drug War." Unpublished Manuscript. (https://bit.1y/2Ao72af).

Lein, Yehezkel. 2003. Behind the Barrier: Human Rights Violations as a Result of Israel's Separation Barrier. B'Tselem. (http://bit.ly/2BM3GA0).

Massey, Douglas S, Karen A Pren and Jorge Durand. 2016. "Why Border Enforcement Backfired." American Journal of Sociology 121(5):1557-1600.

OCHA. 2014. 10 Years Since the ICJ Advisory Opinion. UN Office for the Coordination of Humanitarian Affairs occupied Palestinian territory. (http://bit.1y/2E5XUeX).

Parker, Dominic P, Jeremy D Foltz and David Elsea. 2016. "Unintended Consequences of Sanctions for Human Rights: Conflict Minerals and Infant Mortality." The Journal of Law and Economics 59(4):731-774.

State Comptroller, Israel. 2014. The Treatment of the Police and Government Ministries of The phenomenon of Vehicle Thefts. Technical report State Comptroller. Retrieved October 3, 2017. (http://bit.1y/2FT1XaG).

UNODC. 2018. Global Study on Smuggling of Migrants. Technical report United Nations.

Wastl-Walter, Doris et al. 2014. Borders, fences and walls: State of insecurity? Ashgate Publishing, Ltd. 